\title{
Nano-Scale Topographic Modification of Commercial Pure Titanium Dental Implant to Improve Osseointegration
}

\author{
Ban Nahal Shukur, B.D.S, M.Sc. ${ }^{1}$, Raghdaa Kareem Jassim, B.D.S, M.Sc., Ph.D ${ }^{3}$, \\ Abdalbasit A. Fatihallah, B. D. S, M.Sc., Ph.D², \\ ${ }^{1}$ Assistant Lecturer, College of Dentistry, AL Mustansyria University, Baghdad, Iraq \\ ${ }^{2,3}$ Assistant Professor, College of Dentistry, Baghdad University, Baghdad, Iraq \\ *Corresponding Author: Raghdaa Kareem Jassim, B.D.S, M.Sc., Ph.D
}

\begin{abstract}
The influence of commercially pure titanium (Cp Ti) coatings on the biocompatibility of dental implants using a combination of chemical etching and physical vapor deposition methods were studied. The implants prepared and divided into three groups: without modification (control), surface modified with Ti by thermal evaporation (thermally treated), and surfaces chemically etched with $\mathrm{H}_{2} \mathrm{SO}_{4}$ and $\mathrm{H}_{2} \mathrm{O}_{2}$ before coating with Ti by thermal evaporation deposition (combination treated). For this in vitro experiments, the surfaces characterized by scanning electron microscopy, X-ray diffraction, atomic force microscopy, thickness measurements and microscopy examinations. While, for these in vivo investigations, the implants inserted into the tibia of New Zealand rabbits. A biomechanical tests and histological analysis were performed to understand the bone-implant interface and torque resistance of the implants. The results show that the average removal torque gradually increases and is highest in the combination treated group. In addition, the histological analysis showed improved quality of bone in response to surface nano-modification; the combination treated implants revealed a well-developed mature bone, characterized by bony threads and haversian canal.
\end{abstract}

Keywords: Removal torque; Titanium rod; Rabbit tibia; Acid etching, Thermal evaporation deposition

\section{Introduction}

The biocompatibility of dental implants is strongly associated with interactions between the biomaterial surface and osteoblasts [1]. In this vein, much research has been conducted into how dental implants interact with bone and a significant number of studies have been carried out to investigate improvements of the bone/biomaterials interface [2]. Titanium (Ti) is regularly used as an implant biomaterial due to its mechanical properties and high in vitro and in vivocytocompatibility, allowing direct bone-to-implant contact [3]. In an attempt to increase the amount and quality of the bone-implant interface, different surface treatments have been explored, such as surface machining, acid etching, electro polishing, anodic oxidation, sandblasting and plasma-spraying. These methods induce chemical modifications associated with alterations in surface topography [4], which have been shown to significantly affect the properties of the surface and subsequently the biologic response that occur at the surface [5].

A variety of physical methods have been used to generate bioactive nano-topographies on metal surfaces [6]. For example, physical vapor deposition (PVD) has been applied to create different nano-topographical coatings on $\mathrm{Ti}$ surfaces, which have been used to evaluate the effects of surface chemistry and topography on the cellular and/or tissue response[7,8]. PVD processes include evaporation, sputtering and ion plating. Evaporation is carried out under vacuum (typically $0.1-1 \mathrm{~Pa}$ ), allowing the evaporated atoms to undergo a collision-free transport prior to condensation on the substrate. While high vacuum thermal evaporation has been used to deposit thin films of Ti-6Al-4V onto plates for subsequent cell culture investigations [9].

In this study, four types of nano surface modification used as follows: no surface modification, surface-modified using thermal deposition method, and surface-modified using a combination of chemical etching and thermal deposition method.

\section{Materials and Methods}

\subsection{Sample Preparation}

CP Ti plates grade II was used as the substrate for surface modification investigations. These plates were cut from sheets into small square pieces $(16 \times 17 \times 0.25 \mathrm{~mm}$; length, width and thickness, respectively). Debris and contamination were removed by ultrasonic cleaning in ethanol for $15 \mathrm{~min}$, followed by cleaning in distilled water for $10 \mathrm{~min}$, before drying the plates at room temperature. Then, these plates were divided into four groups as follow: no surface modification (mirror polished from the source; X), surfacemodified using thermal deposition method (X1), and surface-modified using a combination of chemical etching and thermal deposition method (X2).

In group $\mathrm{X} 2$, the plates were treated with equal volumes of $15 \mathrm{~N} \mathrm{H}_{2} \mathrm{SO}_{4}$ and $30 \%$ aqueous $\mathrm{H}_{2} \mathrm{O}_{2}$ for $4 \mathrm{~h}$ under continuous agitation. After that, a vacuum thermal evaporation (Edward Speed Vac unit E306, Germany) approach were applied to coat the nano-Ti powder (Hongwu nanometer, China). nanoTi powder weighing $0.08 \% \mathrm{~g} \cdot \mathrm{wt}$ was used for obtaining a $\mathrm{Ti}$ film with a thickness of $300 \pm 30 \mathrm{~nm}$. the weighed material placed in a molybdenum boat. The distance between the substrate and the boat was $9 \mathrm{~cm}$ and the substrate was at room temperature.

Ti plates placed on the aluminum substrate, while simultaneously placing a glass slide to monitor the growth of the film. After the rotary pump reached $10^{-3} \mathrm{mbar}$ and

\section{Volume 6 Issue 1, January 2017}




\section{International Journal of Science and Research (IJSR) \\ ISSN (Online): 2319-7064}

Index Copernicus Value (2015): 78.96 | Impact Factor (2015): 6.391

diffusion reached $10^{-5} \mathrm{mbar}$, an electrical current passed through the boat. Then the current gradually increased to prevent the boat from breaking, until the boat reddened and glowed upward to reach a high degree of sunshine. The material began to evaporate at $75 \mathrm{~V}$. At this point the voltage was fixed to ensure that the evaporation and deposition processes started with constant deposition rate equal to 87 $\mathrm{nm} / \mathrm{min}$. After that, the current supply switched off and left the system under low pressure for an appropriate period in order to remove excess heat caused by the evaporation process. Then all the samples left in the system to cool, admitting air into the chamber. After coating, the Ti plate oxidized at $600^{\circ} \mathrm{C}$ for $1 \mathrm{~h}$, which was carried out in air in a tubed furnace (Phoenix, USA).

\subsection{Examination of nano-modified surfaces}

\section{X-ray phase analysis}

Using X-ray diffraction (XRD), we examined the structure of the control group (X), the thermally deposition coated group (X1), and the combined chemical etching and thermal deposition group (X2). $\mathrm{Cu} \mathrm{K \alpha}$ target radiation was applied. The 2 øangles were swept from $20-80^{\circ}$ in $1^{\circ}$ steps.

\section{Optical microscopically examination}

All the samples were examined using an optical microscope (Nikon Eclipse ME 600L/441002, Japan) and a digital camera (Type DXM $1200 \mathrm{~F}$ ). This revealed the appearance of the coated surface layer and thermally grown $\mathrm{TiO}_{2}$. We analyzed the micrographs using the Nikon ACT software Version 2.62, 2000.

\section{Scanning electron microscopy(SEM) analysis}

All groups were imaged using SEM (TESCAN VEGA 111, Czech Republic). the device operated at $30.0 \mathrm{kV}$ and examined the surface of the thermally oxidized coated samples at $600^{\circ} \mathrm{C}$. the thickness of the coated layer was measured by using cross sectional examination for X1 and $\mathrm{X} 2$. also measured the $3 \mathrm{D}$ projection in the $\mathrm{X} 1$ sample and rod-like structures in the $\mathrm{X} 2$ sample.

\section{Surface roughness measurements}

The roughnesses of all groups were examined using a scanning probe microscope (AA3000 Angstrom Advanced Inc., USA).

\subsection{Implant preparation}

CP Ti rods used to prepare the screws. Then 30 screws were machined from $\mathrm{CP}$ Ti rods using a lathe machine with a cutting head coated with titanium carbide. The length of the screw was $8 \mathrm{~mm}$ ( $5 \mathrm{~mm}$ threaded and $3 \mathrm{~mm}$ flat) and the pitch height was $1 \mathrm{~mm}$, and $3 \mathrm{~mm}$ in diameter. The screw heads had a slit $1.5 \mathrm{~mm}$ deep and $1 \mathrm{~mm}$ wide, which was used to fit the screwdriver and torque meter during insertion and removal. These screws were thoroughly ultra-sonicated in ethanol for $20 \mathrm{~min}$ to remove debris and contamination and dried at room temperature. Out of the 30 screws, ten screws was surface-modified using the chemical etching method ban and raghdaa2005. Then these implants treated with a solution consisting of $1: 1 \quad 15 \quad \mathrm{NH}_{2} \mathrm{SO}_{4}$ and $30 \%$ aqueous $\mathrm{H}_{2} \mathrm{O}_{2}$ for $4 \mathrm{~h}$ under continuous agitation. then the implants washed with $\mathrm{dH}_{2} \mathrm{O}$ under continuous agitation for
15 min to eliminate acidic residues and dried the implants at room temperature. After etching, we coated the ten implants with Ti powder, following the same procedure performed on the plates. These implants were placed on the substrate and simultaneously placed a glass slide and $\mathrm{Ti}$ plate to acquire measurements. The distance between the implants was 1.5 $\mathrm{cm}$ to allow the vapor to enter between them.

The remaining 20 implant were divided into two groups: the first group contained ten control implants, which remained as machined surfaces, while the second group contained ten dental implants coated using the thermal evaporation method. All screws were sterilized with a gamma irradiation dose of 1000 rad (Gammacell 220) with a Cobalt-60 source. The energy of the used radiation was $1.25 \mathrm{MeV}$. The dose rate was $90.4 \mathrm{rad} / \mathrm{min}$ and the distance between the source of radiation and dental implant was $80 \mathrm{~cm}$. The total time was 23, 49 min. all implants were keptin airtight plastic sheets until operation.

\subsection{Surgery}

Ten adult male New Zealand white rabbits were used weighing $1.75-2 \mathrm{~kg}$. The animals were fed with standard pellets and carrots. the rabbits left days in the same environment for ten before surgical operation. Then a single dose of $10 \mathrm{mg}$ ivermectin subcutaneously injection administered to ensure the animals were parasite free.

The rabbits were divided into two groups. In the first group, eight animals were sacrificed for mechanical testing (torque removal test). In the second group, we sacrificed two animals for histological analysis. in the tibia , three implants were placed: two implants (one control and one thermal treated) in the right tibia and one implant (combination treated) in the left tibia, consequently starting from the medial to distal metaphysic for each animal. all instruments were autoclaved at $121^{\circ} \mathrm{C}$ and 20 bars for $30 \mathrm{~min}$ before the operation.

The required dose of anesthesia and antibiotic was calculated by weighing each rabbit and anaesthetized the rabbits using intramuscular injections of ketamine (25 $\mathrm{mg} / \mathrm{kg}$ ) and xylazine $(17.5 \mathrm{mg} / \mathrm{kg}$ ). Prior to surgery, $20 \%$ lidocaine $(1 \mathrm{cc} / 1 \mathrm{~cm})$ infiltrated into the tibia metaphase. The operation was performed under sterile conditions and gentle surgical technique. Before surgery, we shaved the legs and disinfected the animals using a mixture of iodine and $70 \%$ ethanol. We exposed the tibia metaphysics separately by incision through the skin, fascia and periosteum. We selected the flat surface on the anteromedial aspects of the tibia for implant placement. We drilled under continuous cooling with irrigated saline, making initial holes of $1.8 \mathrm{~mm}$ in diameter and spacing them by $10 \mathrm{~mm}$. We enlarged the holes gradually using 2.2 to $2.6 \mathrm{~mm}$ drills, rinsing the operation site with saline to remove debris. Using a screwdriver, we placed the sterilized implants in the prepared holes, and completed any final screwing with a torque meter (approximately $10 \mathrm{~N} \cdot \mathrm{cm}$ ) before checking the implant for stability. We sutured using absorbable catgut, which we then followed with skin sutures. We sprayed the operation site with a local antibiotic (oxytetracycline spray) and performed post-operative care by giving local and

\section{Volume 6 Issue 1, January 2017 www.ijsr.net}




\section{International Journal of Science and Research (IJSR) \\ ISSN (Online): 2319-7064 \\ Index Copernicus Value (2015): 78.96 | Impact Factor (2015): 6.391}

systemic oxytetracycline $(20 \mathrm{mg} / \mathrm{kg})$ for three days after surgery. We monitored the rabbits daily for two weeks.

\subsection{Mechanical testing (Torque test)}

After a two-week healing period, we used a removal torque meter and mechanically tested eight animals. We anesthetized the animals with the same agent and dose described in the implantation procedure. We made the incision at the lateral side of the tibia, before reflecting the muscles and fascia to expose the implants. We conducted biomechanical testing by engaging the screwdriver of the torque meter into the slit of the implant head to determine the peak torque necessary to unscrew the implant from its bed.

Two animals were used for histological testing and optical microscope analysis. We injected the animals with an overdose of anesthetic solution. We then cut the bone around the implant using a low-speed hand piece and saline solution for cooling. To prepare the bone-implant block for histological analysis, we cut about $5 \mathrm{~mm}$ away from the head of the implant and stored the bone-implant blocks immediately in freshly prepared $10 \%$ buffered formalin.

\section{Results}

\section{X-ray diffraction}

Figure 1 shows X-ray diffraction patterns of all the sample groups. The results reveal that untreated plates exhibit the same diffraction pattern as the Ti coated plates, but with increased intensity, owing to the X-ray penetration of Ti. Thermally deposited $\mathrm{Ti}$ displayed reflection peaks at (100), (002), (101), (102), (110), (103), and (112) around $2 \theta=35.1$, $37.6,40.2,53.0,70.3,63.0$, and 76.3, respectively. These are characteristic $\mathrm{Ti}$ peaks presented in thermally oxidized coated $\mathrm{CP}$ Ti samples, since $\mathrm{Cu}-\mathrm{K} \alpha$ radiation penetrates to a depth of $10-20 \mu \mathrm{m}$, much larger than the thickness of the film. We also observed a reflection peak of (112) around $2 \theta$ $=38.4$, which we assigned to anatase $\mathrm{TiO} 2$. The combination treated plate displayed the following reflection peaks: (100), (101), (102), (110), (103), and (112) around $2 \theta=35.4,39.7$, $52.5,63.0,69.3$, and 75.9, respectively, which are the characteristic peak for Ti. We also noted reflection peaks of (101), (111), (210), (211), and (220) around $2 \theta=36.7,40.4$, $44.4,54.0$, and 57.0, respectively, which are the characteristic peak of rutile $\mathrm{TiO} 2$. We also recorded reflection peaks at (112), (004), and (213) around $2 \theta=38.2$, 39.7 , and 61.5 , respectively, which are the characteristic peaks of anatase $\mathrm{TiO} 2$.. Overall, we report an increase in anatase and rutile $\mathrm{TiO} 2$ peaks in the $\mathrm{X} 2$ group compared with the X1 group.

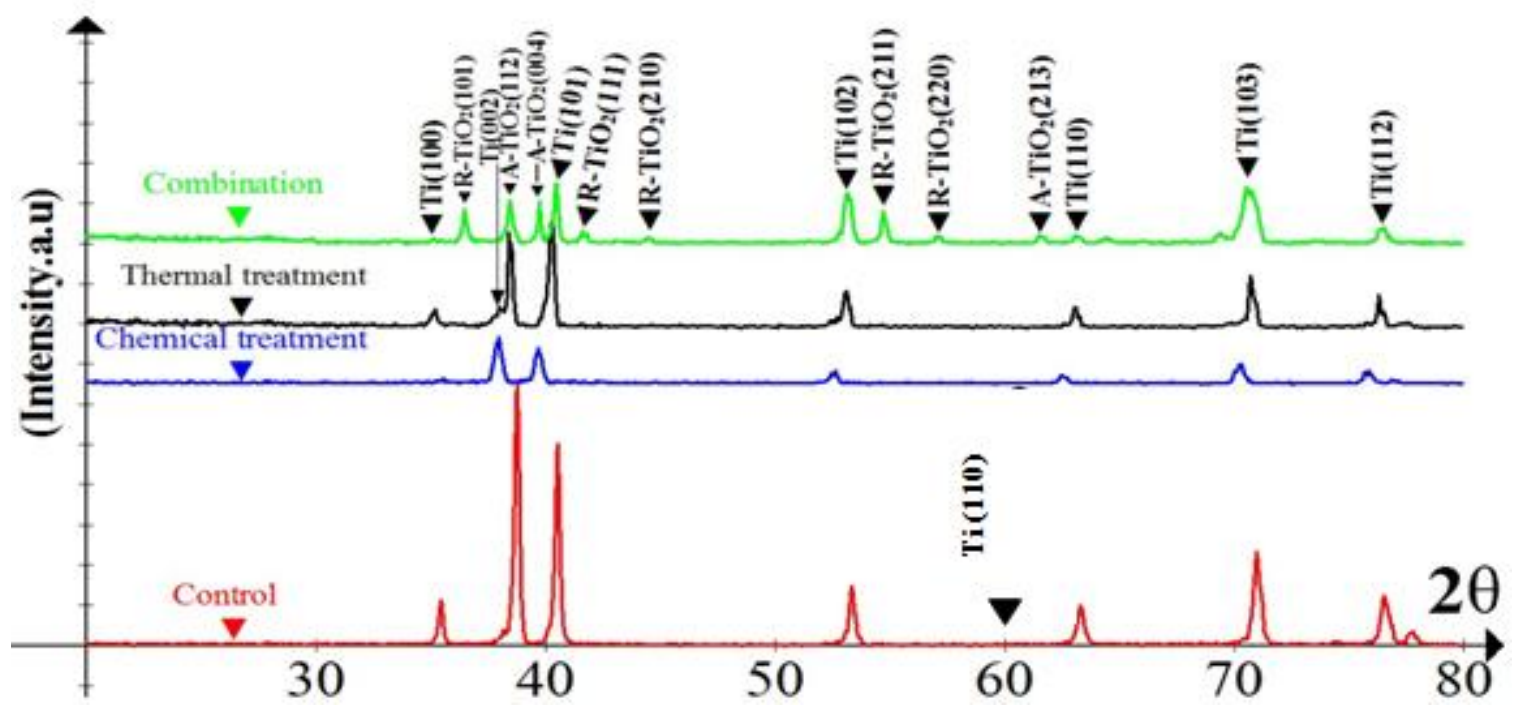

Figure 1: X-ray diffraction patterns of untreated, chemically etched, thermal evaporation nano Ti coated after annealing at $600^{\circ} \mathrm{C}$, combination treated using chemical and thermal methods

\section{Optical microscopy observations}

Figure 2 reveals microscopic observations for the Ti plate coated by unoxidized thermal evaporation. We show that the coating layer is homogenous without cracks. There are scratches visible and the appearance is rough in nature, which is due to the grinding process of plate. The absence of cracks in the coating may suggest that there was no shrinkage in the coating and indicate the homogeneity of the coating layer. Figure 3 shows the coated plate thermally oxidized at $600^{\circ} \mathrm{C}$ for $1 \mathrm{~h}$, which exhibits a homogenous coating layer, gray in color and without cracks.

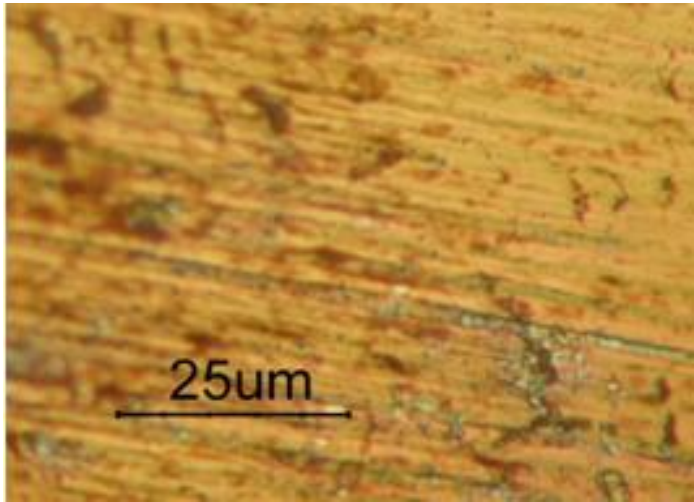

Figure 2: Coated unoxidized plate 


\section{International Journal of Science and Research (IJSR) \\ ISSN (Online): 2319-7064}

Index Copernicus Value (2015): 78.96 | Impact Factor (2015): 6.391

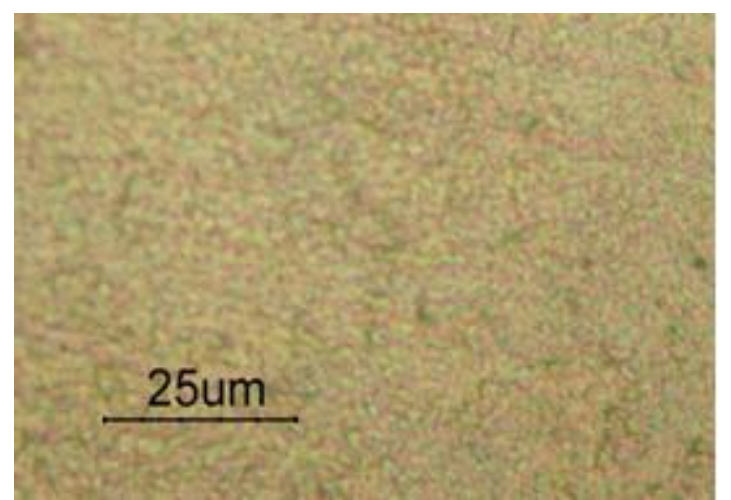

Thickness measurement by SEM

We measured the thickness of X1 and X2 using SEM with cross section as shown in Figure 4 (a, b). The results reveal that the thickness of the coated plate after oxidation was $2.80 \mu \mathrm{m}$ and the thickness of combination treated plate was $1.67 \mu \mathrm{m}$, as shown in Figure 4 (b). This a marked decrease in thickness of the coated layer in the combination treated sample, which may be due to the coating material (nano-CP Ti) entering the pits made by etching. Shown in Figure 5 (b).

Figure 3: Thermally Oxidized coated plate at $600{ }^{\circ} \mathrm{C}$
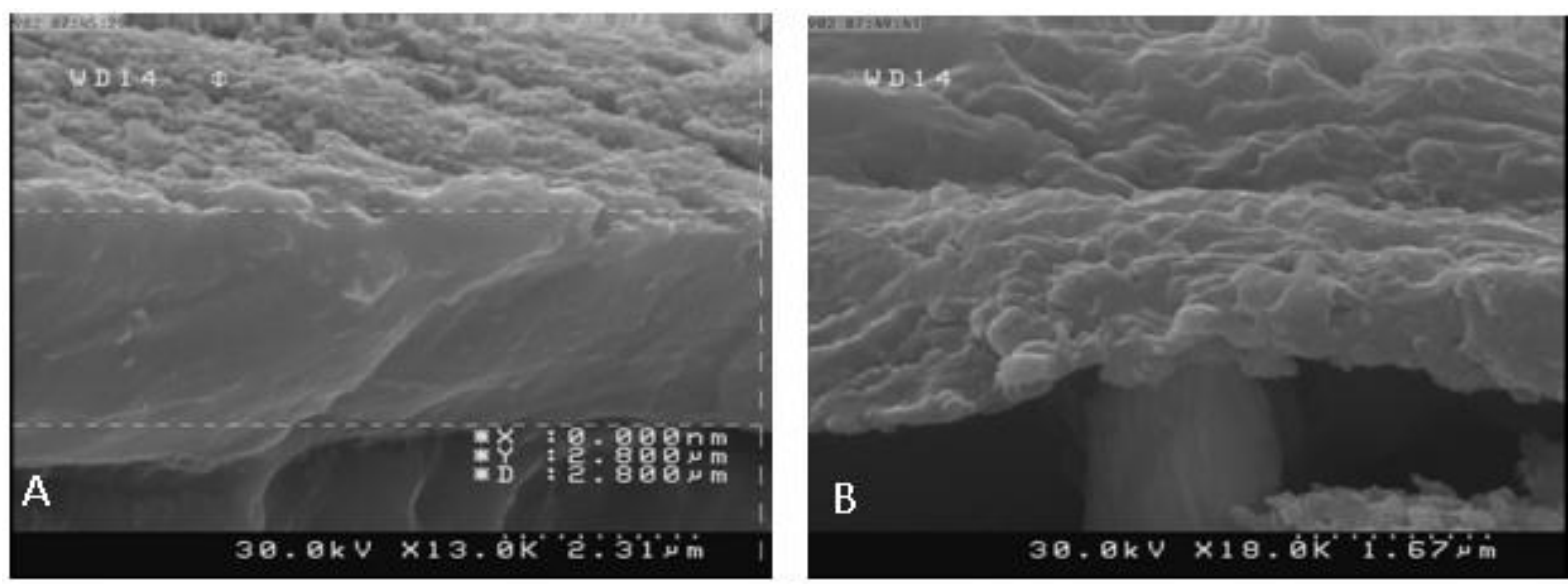

Figure 4 (A\&B): Thickness measurements of Th and CO samples by SEM.

Nano-surface features

Morphological analysis (SEM)

Figure 1.5 (a) shows parallel grooves on the untreated plates, resulting from machining and polishing, with no topographical features. Our SEM micrographs reveal that the Ti samples coated by the thermal evaporation method exhibited many irregular projections, and the surface appeared rough without significant features, as

Figure 5 (c) shows the SEM micrographs for the combination treated group. The image reveals nano-rod-type structures on the surface, distributed in a hexagonal shape, which may explain the role of etching in forming these nano-rods. The 3D measurements of $\mathrm{X} 1$ coated plates are shown in Figure 6 (a), which we measured as $280 \times 431.3$ $\mathrm{nm}$ height and depth, respectively. The 3D measurements of the rod-like structure on the X2 plate are shown in Figure 6 (b), which we measured at $366.7 \times 371.9 \mathrm{~nm}$ for the $\mathrm{Y}$ and $\mathrm{D}$ axis, height and depth, respectively.

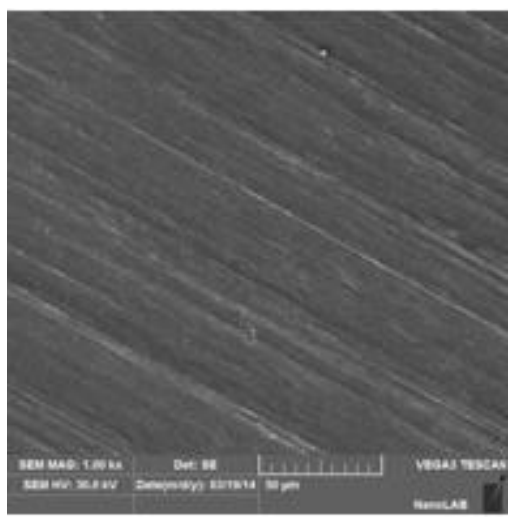

(A) Control

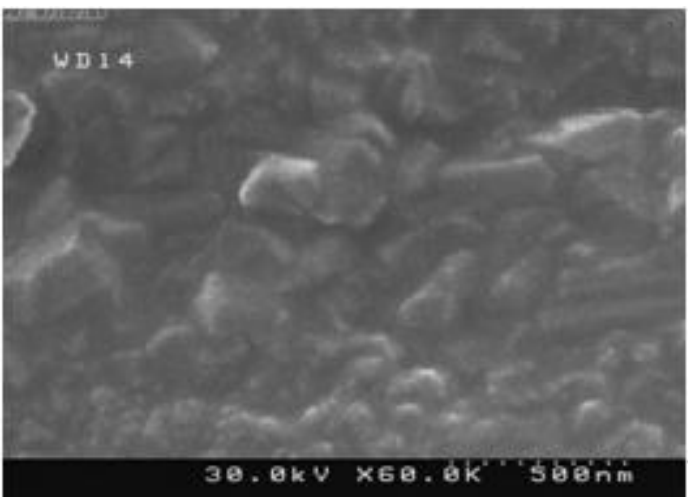

(B) Nano CPTi powder coated by thermal evaporation method

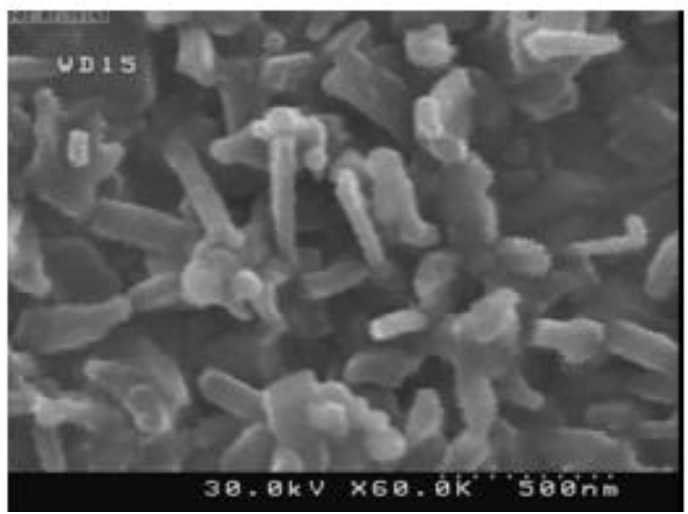

(C)Combination treated plate using etching and thermal deposition method.

Figure 5: SEM for all tested groups

Volume 6 Issue 1, January 2017 www.ijsr.net 


\section{International Journal of Science and Research (IJSR) \\ ISSN (Online): 2319-7064}

Index Copernicus Value (2015): 78.96 | Impact Factor (2015): 6.391
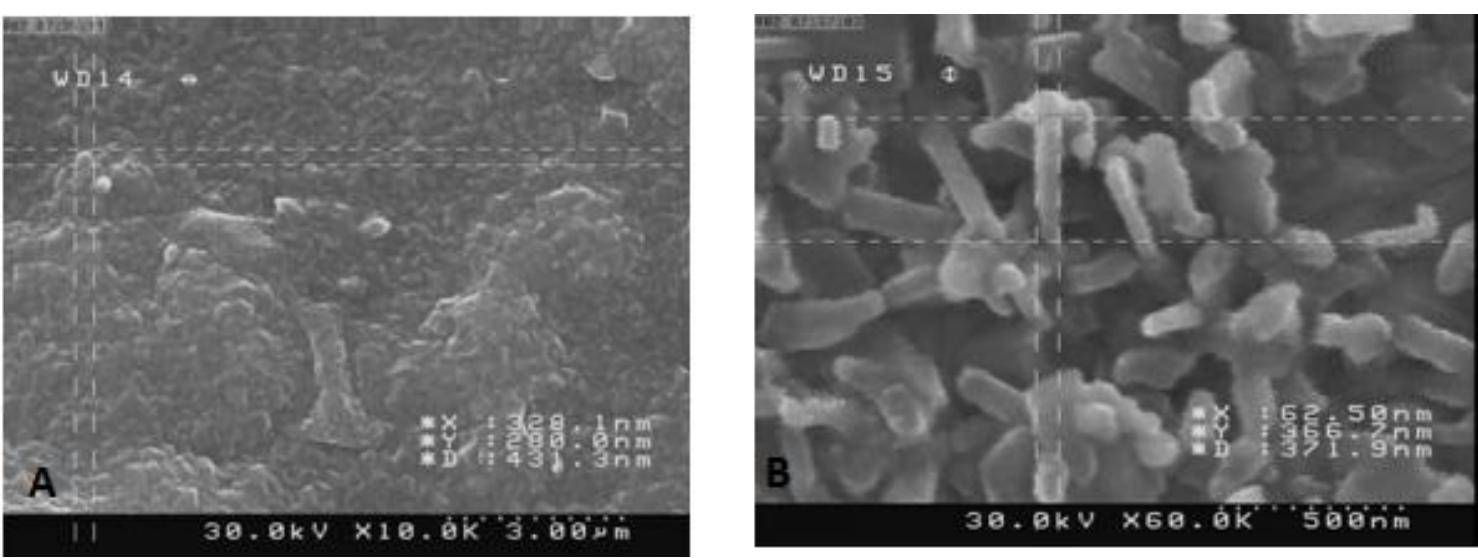

Figure 6: $3 \mathrm{D}$ measurements for projection and rod like structure of $\mathrm{X} 1$ and $\mathrm{X} 2$ samples

Surface roughness analysis

AFM topographies of the Ti surfaces are shown in Figure 7 (a). We observed grooves of mechanical polishing on the untreated surface with an average roughness of $7.37 \mathrm{~nm}$. The roughness of the $\mathrm{Ti}$ coated plate by thermal evaporation method is shown in Figure 7 (b). The image reveals small embedded nodules with an average roughness of $25.1 \mathrm{~nm}$. The same specimen after oxidation appeared with peaks and projections with an average roughness increasing to 29.8 $\mathrm{nm}$, as showed in Figure 7 (c). Before oxidation, due to the particle size of Ti powder $(40 \mathrm{~nm})$, the roughness was in the nano-scale. However, after oxidation, we noted an increase in roughness as can be seen from the peaks that appear on the surface. We report the diameter of the grains increased with oxidation, which leads to an increase in surface roughness, although not strictly linearly. This is in agreement with Kaiyong et al. Meanwhile, the roughness of the combination sample decreased compared with the roughness caused by etching and oxidation, which could be due to a decrease in the average diameter of the grain, as shown in Figure 7 (d). Table 1 summarizes the surface roughness and average grain diameters in our experiments.

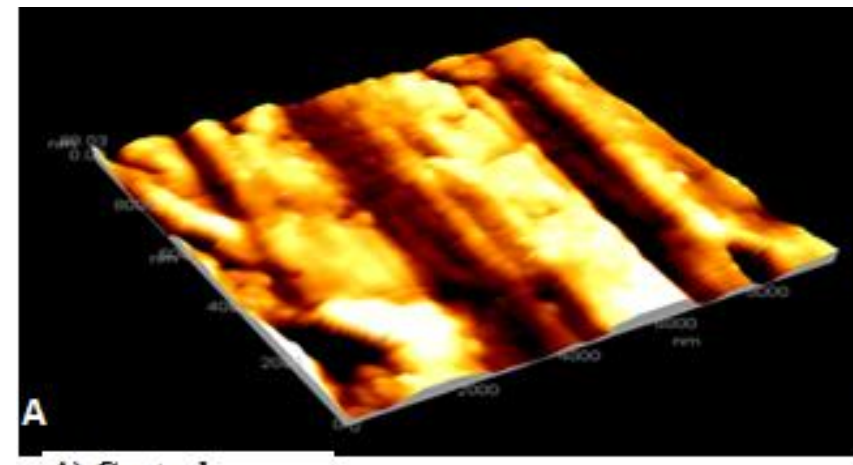

A) Control

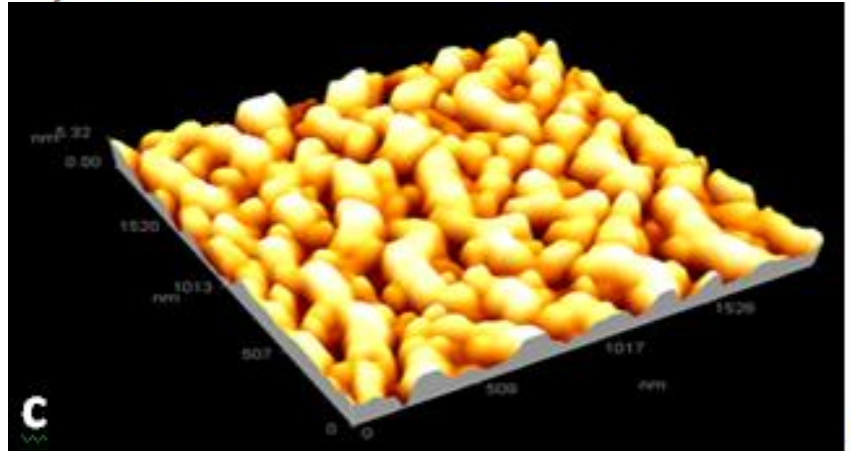

(C) Thermally oxidized coated plate at $600^{\circ} \mathrm{C}$

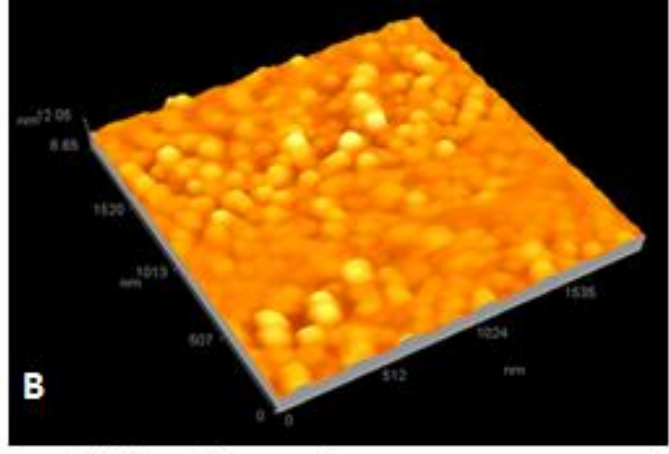

(B) Nano Ti coated

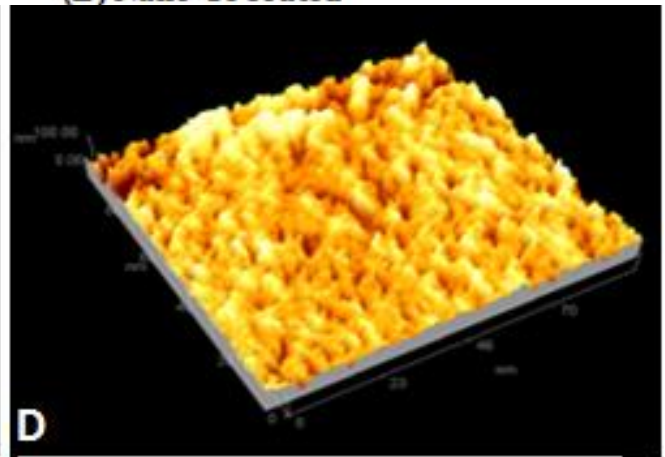

(D)Combination treated plate

Figure 7: AFM topographies of CPTi surfaces

Table 1: Roughness values obtained from AFM images of various surface treated samples

\begin{tabular}{|c|c|c|}
\hline Group & $\begin{array}{c}\text { Avg. Diameter } \\
\text { of grain } \mathrm{nm}\end{array}$ & $\begin{array}{c}\text { Roughness } \\
\text { average } \mathrm{nm}\end{array}$ \\
\hline Control(untreated) & 222.15 & 7.37 \\
\hline Nano Ti coating & 94.92 & 25.1 \\
\hline Thermally oxidized coating & 103.85 & 29.8 \\
\hline combination & 1.27 & 27.7 \\
\hline
\end{tabular}

In vivo experiments

\section{Clinical observations}

All rabbits tolerated the implantation well after surgery and moved normally within one week. One rabbit suffered from tibia fracture and was replaced with another rabbit. At sacrifice, we did not note any signs of gross infection, tissue reaction or any other negative clinical observations around

Volume 6 Issue 1, January 2017 


\section{International Journal of Science and Research (IJSR) \\ ISSN (Online): 2319-7064 \\ Index Copernicus Value (2015): 78.96 | Impact Factor (2015): 6.391}

the implant sites in any of the animals. At the day of sacrifice, we found all of the implants stable in the bone; they could not be moved with manual force and there were no detectable peri-implant bone defects at the coronal aspect of any implant screw.

We chose the rabbit animal model for our in vivo experiments, owing to its ease of manipulation and rapid bone healing response compared to other models[11].The tibia sites in the rabbit were chosen to mimic clinical situation, because the dimensions of this bone correspond well with human alveolar space. Moreover, surgically, this model provides low morbidity with easy access to the medial proximal tibia for implant placement. The morphologic characteristics of the rabbit tibia allow for implant fixture to engage the cortical bone at its coronal aspect and marrow in the apical area[12].Primary stability is considered a key factor for the clinical success of dental implants, and is determined by the density of the bone at the site, the surgical technique and the design of the implant [13]. While, gradually increasing the size of drilling until reaches the final diameter of $2.6 \mathrm{~mm}$ increases compression and thereby the stability of the implant during insertion [14].

\section{Mechanical testing}

Table 2 and Figure 8 show removal torque values for the control dental implants, surface implants modified using thermal deposition, and surface implants modified using a combination of chemical etching and thermal deposition. A higher torque value was needed to remove the combination treated screw (mean value of $\mathbf{5 1 . 2 5 0} \mathbf{N} \cdot \mathbf{c m}$ ) and the lowest torque value was needed to remove the control (machined screw; mean value of $\mathbf{1 2 . 6 2 5} \mathbf{N} \cdot \mathbf{c m}$ ).

Table 2: Removal torque mean values for all groups after 2

\begin{tabular}{|c|c|c|c|c|c|}
\hline Sample & d.f & S.S & M.S & F- cal. & P-value \\
\hline Between Groups & 2 & 7157.583 & 3578.792 & & \\
\hline Within Groups & 21 & 436.250 & 20.774 & 172.274 & 0.000 \\
\hline Total & 23 & 7593.833 & -- & -- & -- \\
\hline \multicolumn{7}{|c|}{ P-value: Highly significant. } \\
\hline
\end{tabular}

Table 3 shows the equality of means between all groups of implants, which demonstrate significant differences at $\mathrm{P} \leq$ 0.01 with two degrees of freedom (tested by ANOVA). In particular, the table shows highly significant differences in torque mean value among all tested groups. Figure 8 shows a significant difference (Duncan's test) of torque mean values among different groups after the two weeks healing period, while no significant differences are noted between the thermal and combination group.

Table 3: Equality of means of removal torque value by ANOVA for all groups

\begin{tabular}{|c|c|c|c|}
\hline Group (Treatment) & $\mathrm{N}$ & Mean \pm SD $(\mathrm{N} . c m)$ & Range \\
\hline Control & 8 & $12.625 \pm 0.517$ & $12-13$ \\
\hline Thermal & 8 & $46.875 \pm 5.938$ & $40-55$ \\
\hline Combination & 8 & $51.250 \pm 5.175$ & $40-55$ \\
\hline
\end{tabular}

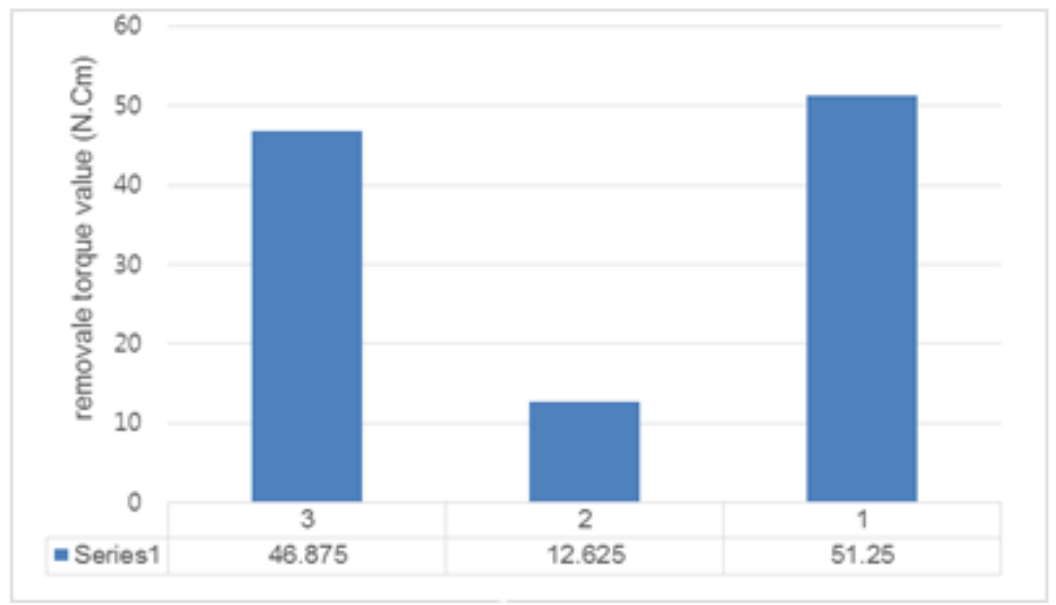

Different letter in columns are significant difference

Similar letter in columns are none significant difference, Level of sig. ** $(\mathrm{P} \leq 0.05)$.

Figure 8: Bar histogram for all tested groups after 2 weeks Interval

\section{Histological analysis}

Figure $9(\mathbf{a}, \mathbf{b})$ shows the trabecular bone in the $\mathrm{X} 1$ and $\mathrm{X} 2$ treated groups. Osteoblast and osteocyte are shown in Figure 9 (c, d). In particular, the bone trabeculae for the X2 treated implants are thick, as demonstrated in Fig 9 (d). We noted late stage development of the haversian system, formed with arranged osteocytes around the central canal, as shown in Figure 9 (e).

In this study, we chose histological analysis, since it is the method of highest reliability to evaluate implant stability and can be performed at any time of the implantation, as stated by Atsumi et al in 2007[14]. Our histological analysis for all groups revealed new bone trabeculae formation with active osteoblasts and osteocytes on the borders. Furthermore, we did not observe any inflammatory reaction in our experimental periods, regardless of the type of implant and the duration of the implantation. This is in agreement with the results of Mano et al., in 2002[15]. 


\section{International Journal of Science and Research (IJSR) \\ ISSN (Online): 2319-7064}

Index Copernicus Value (2015): 78.96 | Impact Factor (2015): 6.391

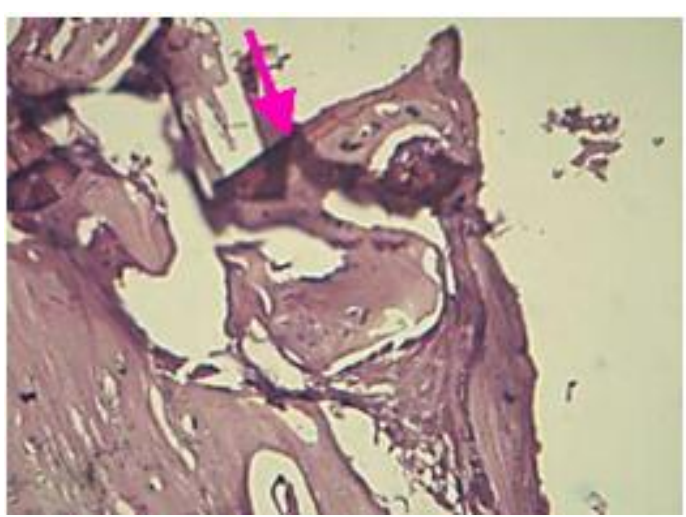

Figure 9 (a): View for trabeculated threads for( $\mathrm{X} 1) \mathrm{H} \& \mathrm{E} \times 10$.

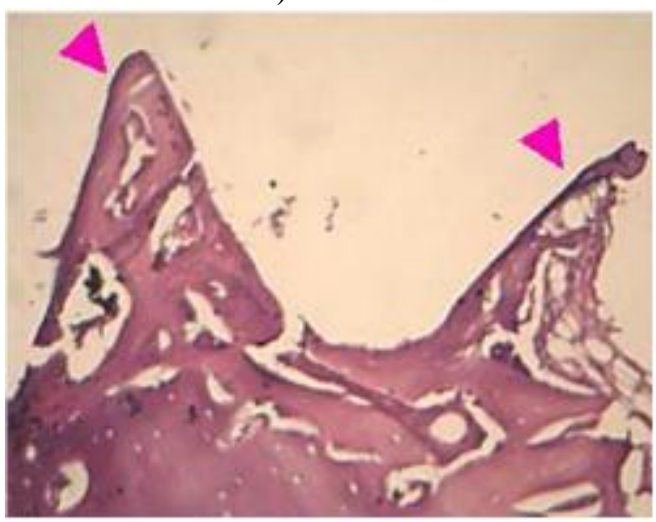

Figure 9 (b): View for histological section of combination modified dental implant(X2) shows well developed boney threads (arrow heads) H\&E $\times 20$

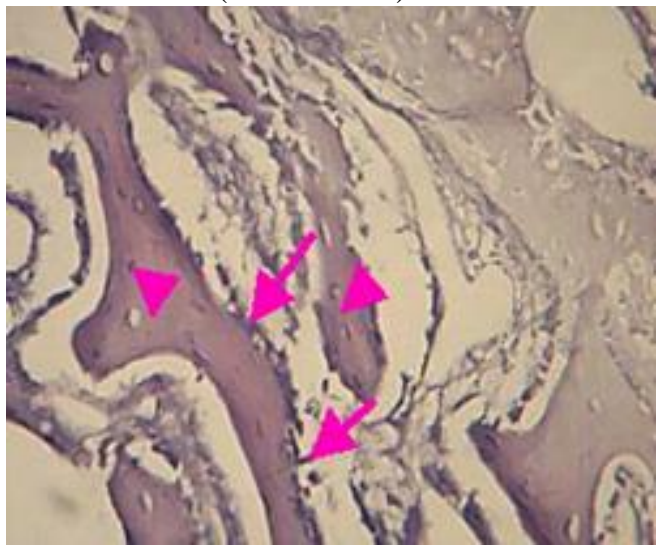

Figure 9 (c): Magnifying view for bone trabeculae (BT) for thermal deposition implant shows Osteocytes (arrow head) $\mathrm{H} \& \mathrm{E} \times 20$

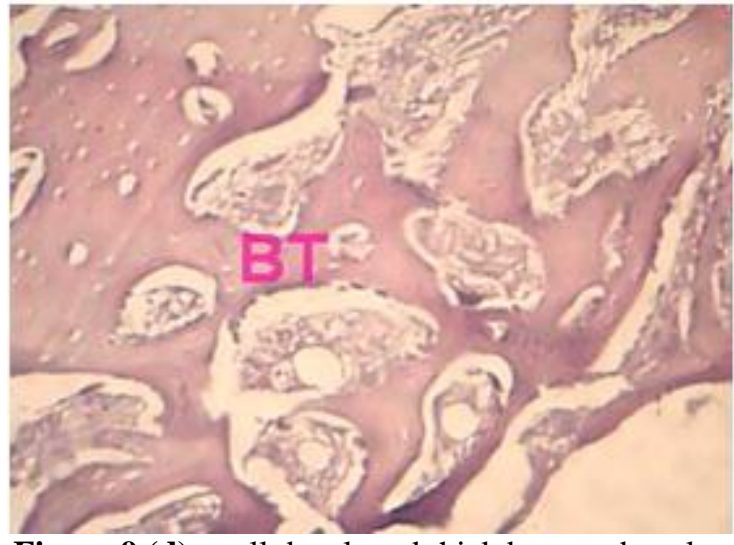

Figure 9 (d): well developed thick bone trabeculae (BT)filled implant print $\mathrm{H} \& \mathrm{E} \times 20$

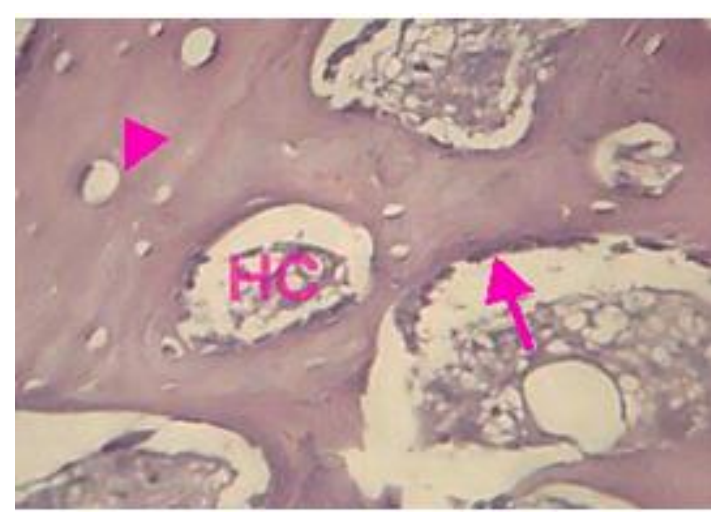

Figure 9 (e): Magnifying view for previous fig shows Haversian canal (HC), Osteoblast (arrow), osteocyte (arrow head) $\mathrm{H} \& \mathrm{E} \times 40$

Figure 9: Histological view of all tested group

\section{Discussions}

Since the anatomic surface of bone cannot be controlled, surface topography of an implant can be designed by making porous and/or by coating the implant surface with other suitable materials to increase bone implant contact [17].The application of nanotechnology to biomedical surfaces is explained by the ability of cells to interact with nano-metric features. Improvement of the bone forming activity at the bone-implant interface is committed to nanoscale features that have the ability to induce the differentiation of stem cells along the osteogenic pathway [16]. The X1-treated dental implants showed higher removal torque values than the $\mathrm{X}$ group. This is due to impacting the external crystal phase of the implant $\mathrm{Ti}$ core material (rutile, anatase and amorphous) to create a $\mathrm{Ti}$ film.

Our results highlight that the nanoscale topography created with anatase Ti promoted the best in vitroeffects in terms of cell adhesion, proliferation and differentiation [18]. Our XRD results demonstrated that the Ti coated by thermal deposition had a high intensity peak, corresponding to anatase $\mathrm{TiO}_{2}$. The $\mathrm{X} 2$ treated dental implant showed more anatase and rutile $\mathrm{TiO}_{2}$ than the $\mathrm{X} 1$ treated dental implants. This is in agreement with Sul et al. 2005[19], who showed several microarc oxidized implant surfaces exhibited different crystal structures (amorphous, anatase, anatase/rutile mixture) in the rabbit tibia model. Both anatase and anatase/rutile surfaces exhibited better torque resistance compared with amorphous surfaces. Moreover, anatase or rutile surfaces showed better cellular responses, such as increased adhesion, proliferation expression of osteoblastic markers (procollagen typeI peptide, osteocalcin and alkaline phosphatase).

The trabecular threads have been seen in both $\mathrm{X} 1$ and $\mathrm{X} 2$ treated groups. The bone trabeculae were thick for the combination treated implant compared with the other groups. This is due to the surface roughness, which is of great importance in stimulating bone production and forming nano-rods. Also, our histological microphotographs showed late stage development of future compact bone had already formed with arranged osteocytes around the central canal, which may be due to the presence of anatase and rutile $\mathrm{Ti}$ as well as increased surface roughness. 


\section{International Journal of Science and Research (IJSR) \\ ISSN (Online): 2319-7064}

Index Copernicus Value (2015): 78.96 | Impact Factor (2015): 6.391

\section{Conclusion}

PVD method can be considered as a suitable method for obtaining nano-feature morphology and statically significant high removal torque mean value. We hypothesize that rapid bone formation in response to the combination treated nanoTi dental implants are dependent on better biocompatibility of the material and on surface topography, which greatly affects the histological and biomechanical properties of the interface.

\section{References}

[1] Brama M, Rhodes N, Hunt J, Ricci A, Teghil R, Migliaccio S, et al.. Effect of titanium carbide coating on the osseointegration response in vitro and in vivo. Biomaterials 2007; 28,595-608.

[2] Rosa AL, De Oliveira CS, Beloti MM, Xavier SP, De Oliveira PT.Effect of microcapsules containing TAK778 on bone formation around osseointegrated implants: histomorphometric analysis in dogs. Implant Dent 2006; 15, 97-103.

[3] Klokkevold PR, Nishimura RD, Adachi M, Caputo A. Osseointegration enhanced by chemical etching of the titanium surface. A torque removal study in the rabbits. Clin Oral Implants Res 1997; 8,442-447.

[4] Takebe J, Ito S, Champagne CM, Cooper LF, Ishibashi $\mathrm{K}$. Anodic oxidation and hydrothermal treatment of commercially pure titanium surfaces increases expression of bone morphogenetic protein-2 in the adherent macrophage cell line J774A. J Biomed Mater Res A 2007; 80,711-718.

[5] Keller JC, Draughn RA, Wrightman JP, Dougherty WJ, Meletiou SD. Characterization of sterilized CP titanium implant surfaces. Int J Oral Maxillofac Implants 1990; 5,360-369.

[6] Ogawa T., Saruwatari L., Takeuchi K., Aita H., Ohno N., Ti nanonodular structureing for bone integration and regeneration Dent. Res 2008; 87(8), 751-756.

[7] Großner-Schreiber B., Herzog M., Hedderich J., Duck A., Hannig M.and Griepentrog M., Clin. Oral Implants Res 2006;17, 736.

[8] Hacking S. A., Zuraw M., Harvey E. J., Tanzer M., Krygier J. J., Bobyn J. D., A physical vapor deposition method for controlled evaluation of biological response to biomaterial chemistry and topography, Biomed. Mater. Res. A 2007; 82, 179-187.

[9] Koontz CS, Ramp WK, Peindl RD, Kaysinger KK, Harrow ME.Comparison of growth and metabolism of avian osteoblasts on polished disks versus thin films of titanium alloy 1998; 42(2), 238-44.

[10]Kaiyong Cai,Michael Muller,Jorg Bossert,Annett Rechtenbach,Klaus D.Jandt.surface structure and omposition of flat titanium thin film as a function of film thickness and evaporation rate;Applied Surface Sciene 2005; 250, 252-267.

[11] Kim E.S., Park E.J., Choung P.H. Platelet concentration and its effect on bone formation in calvarial defects: An experimental study in rabbits: J Prosth Dent 2001; 86, 428-33.

[12] Dahlin C, Sennerby L, Lenkholm U, Linde A, Nyman S. Generation of New Bone around Titanium Implant using membrane technique: An experimental study in rabbits. Int J Oral Maxillofac Implant 1989; 4 (1), 19-25.

[13] Friberg B, Jemt T, Lekholm U. Early failures in 4,641 consecutively placed Brånemark dental implants: a study from stage 1 surgery to the connection of completed prostheses. Int J Oral Maxillofac Implants $1991 ; 6,142-146$.

[14] Atsumi M, park S, wang H. Methods used to Assess implant stability: Current status. Int J Oral Maxillofac Implant 2007; 22, 743-754.

[15] Mano T, Ueyama Y, Ishikawa K, Matsumura T, Suzuki $\mathrm{K}$. Initial tissue response to a titanium implant coated with apatite at room temperature using a blast coating method. Biomaterials 2002; 23, 1931-36.

[16] Variola F.; Yi, J.H.; Richert, L.; Wuest, J.D.; Rosei, F.; Nanci, A. Tailoring the surface properties of Ti6Al4V by controlled chemical oxidation. Biomaterials 2008; 29: $1285-1298$

[17] Sean S. Kohles, Melissa B. Clark, Christopher A. Brown, James N. Kennedy,Direct assessment of profilometric roughness variability from typical implant surface types, The int $\mathbf{J}$ of oral \& Maxil Implants $2004 ; 19(4),: 510-516$.

[18]He J, Zhou W, Zhou X, Zhong X, Zhang X, Wan P, Zhu $\mathrm{B}$, Chen W. The anatase phase of nanotopography titania plays an important role on osteoblast cell morphology and proliferation. J Mater Sci Mater Med 2008; 19(11), 3465-72.

[19] Sul, Y.T.; Johansson, C.; Wennerberg, A.; Cho, L.R.; Chang, B.S. \& Albrektsson, T. Optimum surface properties of oxidized implants for reinforcement of osseointegration: surface chemistry, oxide thickness, porosity, roughness, and crystal structure. The International Journal of Oral and Maxillofacial Implants 2005; 20(3), 349-359. 